\title{
The Technology Development and Management of Smart Manufacturing System: A Review On Theoretical and Technological Perspectives
}

\author{
Md. Al-Amin, PhD student \\ Md Tanjim Hossain, PhD student \\ Wilson College of Textiles \\ North Carolina State University, USA \\ Md Jahidul Islam, MS student \\ Management Information System \\ Lamar University, USA
}

Doi:10.19044/esj.2021.v17n43p170

Submitted: 27 October 2021

Accepted: 23 December 2021

Published: 31 December 2021
Copyright 2021 Author(s)

Under Creative Commons BY-NC-ND 4.0 OPEN ACCESS

Cite As:

Al-Amin M., Hossain M. T.,\& Islam M. J., The Technology Development and Management of Smart Manufacturing System: A Review On Theoretical and Technological Perspectives European Scientific Journal, ESJ, 17(43), 170.

https://doi.org/10.19044/esj.2021.v17n43p170

\begin{abstract}
This paper encompasses a state-of-the-art review on smart manufacturing system (SMS), focusing on theoretical relevance to technology development and technology management. The theoretical foundation of technology development has been reviewed based on the Rogers' Diffusion of Innovation (DoI) theory and technology management has been focused on the basis of Technology Strategy Model (TSM) of Rieck and Dickson to shape the paper with theory of Management of Technology (MOT). A patent on SMS has been discussed to show how different technologies are integrated into this system. The characteristics of SMS have discussed the overall aspects of this future technological system. The the global textile complex has been depicted with a proposed SMS model of the apparel production unit. This study integrates the latest articles and technology on future manufacturing system perspectives, which gives a robust idea of minimizing human interaction and maximizing the production efficiency in the manufacturing industry. The cyber-physical system, AI, ERP, digital twin, big data, additive manufacturing, cloud manufacturing, simulation, and vertical and horizontal
\end{abstract}


integration have been identified as the major components of SMS. A brief model of SMS in the apparel production system demonstrated how SMS works in the industry level. The researchers on smart manufacturing can take away the above insights into their future research to take SMS research more forward.

Keywords: Smart Manufacturing, Industry 4.0, Technolgy management, Technology Development. Technology Theory.

\section{Introduction}

Traditional manufacturing systems include the designs of relatively rigid hierarchical architectures where the scopes are limited to the production arrangement and operation of resources. This rigid architecture also leads to the complexity of reprocessing the prevailing manufacturing capacity. ( $\mathrm{Lu} \&$ $\mathrm{Ju}, 2017)$. In recent times new technologies are penetrating the manufacturing system and serving as crucial determinants for the automated manufacturing industry of the current industrial revolution to address the future challenges of providing progressively customized requirements, advanced quality, and shorter lead time by promoting manufacturing systems to a smart level (Zheng et al., 2018). The integration of technologies has enormous significance in achieving the organizational objectives to establish an automated industry in the era of the industrial revolution. For instance, enterprise modeling and reference technology methods are needed for analyzing, designing, planning, and implementing system integration, whereas knowledge and technology on data aspects and metadata are required to achieve the information exchange among systems ( $\mathrm{Li}$ et al., 2018). This integration of technologies in the manufacturing industry is transforming the industry towards smart manufacturing, which synthesizes the advanced automated technologies and digital platform. Smart manufacturing is not only integrating the technologies but also managing the societal, environmental and knowledge workforces care. (Feng et al., 2017). The digitalization in manufacturing industry involves several numbers of technological advancements that represent mostly in the forms of automation such as cyber-physical system, which is the automatic assemblages of objects that communicate through the Internet of things (IoT) and apply new sensor technologies and real-time computing techniques (Krzywdzinski, 2017). The development and management of this new system of complex manufacturing system offers enormous challenges to get the best out of it.

The development and innovation of any new technology provides both new prospects and challenges for the industry. Apart from increasing the annual profit margin, the technology innovation may challenge the entire production and supply chain system, which determines the global 
competitiveness of any enterprise (Gaimon, 2008). On the other hand, technology management includes the active identification, selection, procurement, development, exploitation and protection of technologies that are needed to maintain and grow a market position and business performance pertaining to the company's objectives. Technology management requires effective linkage between the technological resources and several management processes (Phaal et al., 2004). Thus, with the rapid progress in different module of the process, the control of manufacturing system has been a complex process from development to management to get the maximum flexibility (Calinescu et al., 1998).

Moreover, a business system stands based on the range of technological issues, values, and relationships, that are managed and understood by managerial frameworks, theories, and universal languages (McCarthy, 2003). Those complexities of manufacturing system can be explained with the help of existing and relevant theories as theory is a set of assumptions that can attempt to explain or predict a social or technological phenomenon to understand the world, which is used to conceptualize and explain systematic observations on complex phenomena and behaviors (Thomas, 2017). Since SMS is a new paradigm of manufacturing system, that includes many other integrations of technology and complexity. The researchers, developers, and early adopters face difficulties to start on their way to perceive its new systematic approach to dvelope and manage afterwards (Rogers, 1983). Theoretical relevance could explain these complexities in a convenient and understandable way to those relevant stakeholders. Very few literatures have discussed this new manufacturing system and its complexities based on theoretical point of view. Therefore, the objectives of this study is to discuss the technology development of SMS and its management on the basis of existing theory of technology development and technology management.

\section{Methodology}

This study includes a twofold review. The first part basically focuses on the two major theoretical foundations, such as technology development and technology management. Rogers' diffusion of innovation (DoI) theory has been taken as the basis of technology development, while technology strategy model of Rieck and Dickson (1993) has been taken as the basis of technology management review. These two theories have been reviewed in consideration of innovation and management perspectives. Going forward in the second part, SMS has been discussed as per the theoretical relevances. After that, its major components are identified and discussed. A model patent workshop also has been described with its working pattern. As SMS is a new manufacturing paradigm, its characteristics also have been 
reviewed. Finally, the application of SMS in the real world has been demonstrated with its application in the global textile complex.

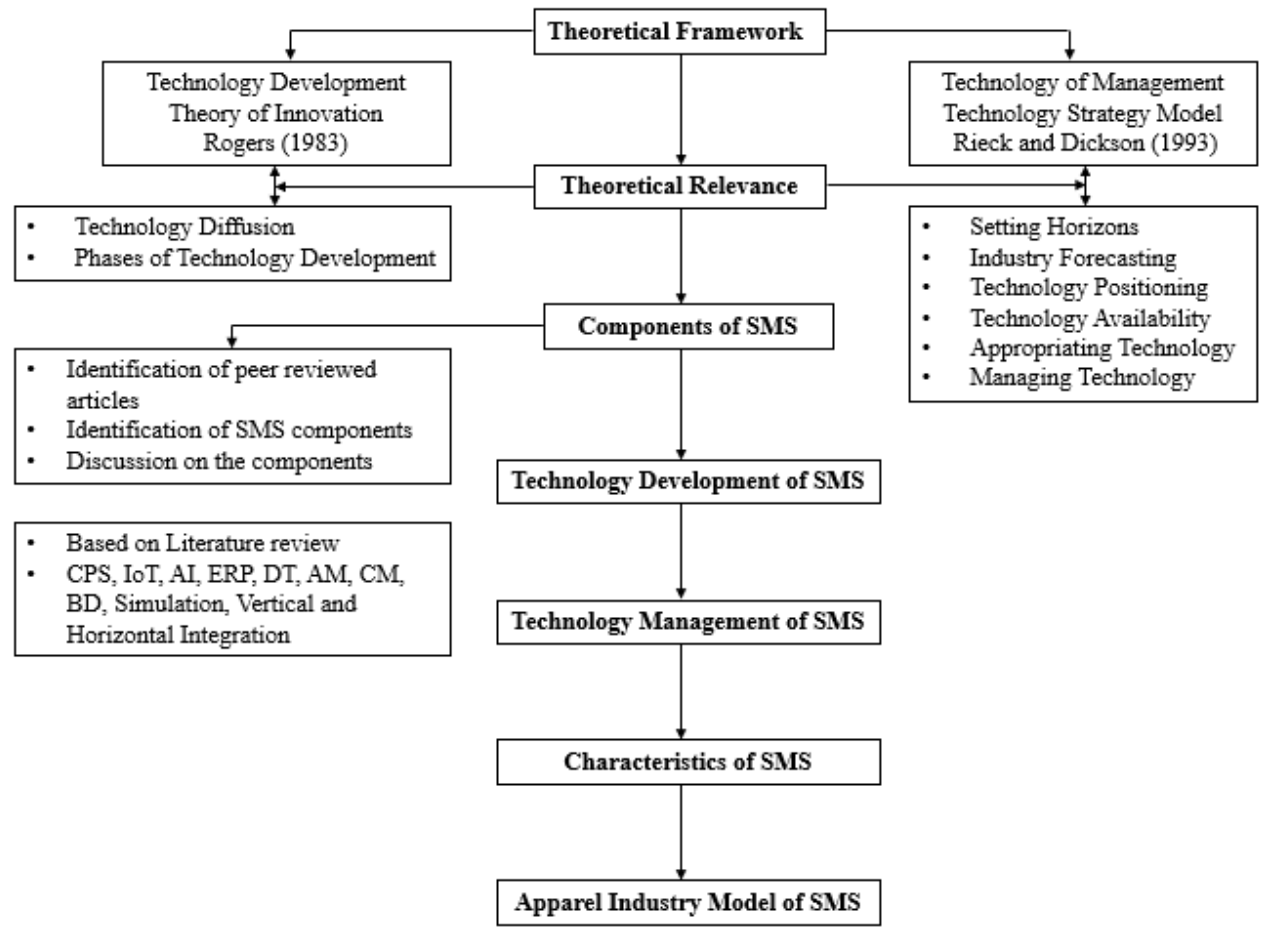

Figure 1. Methodology flowchart.

\section{Theoretical Framework}

\section{Rogers' Diffusion of Innovation Theory}

The span of technology from evolution to a successful implementation is a long and complex process that depends on other technologies, such as an interrelationship of information and resources in the interrelated complex systems for mutual adaptations within the environment. (Mario, 2019). The initial stages of any technology have been explained in many literatures using Rogers' DoI theory, where the author used the word "innovation" as the synonym of "technology" (Sahin, 2006). Rogers (1983) defined diffusion as "the process by which an innovation is communicated through certain channels over time among the members of a social system" (p.05). Therefore, diffusion has four elements, such as (i) innovation (ii) communication channel (iii) time, and (iv) social system.

Innovation. Rogers (1983) defined innovation as "an idea, practice, or object that is perceived as new by an individual or other unit of adoption" (p. 11). All the innovations that Rogers discussed are technological innovation, where technology is a design for instrumental action that lessens the ambiguity in the cause-effect relationships engaged in accomplishing the desired outcome. 
Technology usually consists of two components, such as hardware and software. Hardware signifies the physical or material objects of technology, such as transistors and semiconductors. On the other hand, software embodies the tools based on information of technology, such as coded commands and information. Rogers (1983) conceptualized five main steps in innovationdecision process, such as (i) knowledge (ii) persuasion (iii) decision (iv) implementation (v) and confirmation. These five steps help diffuse knowledge from innovation through implementation to the adoption process. Knowledge takes place when a person or other decision-making unit is exposed to the innovation's life and gains some insight into how it performs (Rogers, 1983). Persuasion happens when a person or other decision-making unit makes a positive or negative approach toward innovation (Rogers, 1983). Decision comes when a person or other decision-making unit interacts in activities that result in a choice to adoption or rejection of the innovation (Rogers, 1983). Implementation takes place when a person or other decision-making unit applies an innovation into use(Rogers, 1983). Confirmation occurs when a person or other decision-making unit looks for reinforcement of an innovation decision that has already been applied, but it can be reversed if it is exposed to conflicting messages on the innovation (Rogers, 1983).

Communication channel. Rogers (1983) defined the communication channel as "the means by which messages get from one individual to another" (p. 17). Rogers categorized communication channels into two segments, such as mass media channels and interpersonal channels. Mass media channels involve the means of transmitting messages through mass media, which enable few individuals to reach an audience of many, for instance, radio, television, and newspaper. On the other hand, Rogers (1983) addressed interpersonal channels as superior over mass media since it is more effective to persuade an individual to adopt new technology. Interpersonal channels are used to exchange messages between two or more individuals.

Time. Rogers (1983) stated time as an important element in the diffusion process. Time is always independent of any event, although it is an important part of any activity. Time is an obvious aspect of the communication process, such as innovation, adoption, and diffusion, or rejection.

Social System. Rogers (1983) defined the social system as "a set of interrelated units that are engaged in joint problem solving to accomplish a common goal" (p. 24). He also stated that a social system could consist of all the members or units of a system or subsystem, such as all the medical doctors in a hospital or all the workers and personnel of a manufacturing enterprise. When all the individuals share their information to accomplish a certain goal, the sharing of information binds the system together. 


\section{Phases of Technology Development}

Rogers (1983) stated four phases that typically take place in developing new technology in the industrial enterprise, such as innovation, imitation, technological competition, and standardization (p.141).

1. Innovation- an uncertain period with several trial-and-error problemsolving leads to the innovation where the production undergoes at a small scale in a garage-like small facility, such as the bioengineering industry (Rogers, 1983).

2. Imitation- many enterprises customize the basic innovation and gradually improve through research and development (R\&D) according to the demand of the market. Thus, the enterprise spinoffs new firms for a new product launch, for example, solar collector industry (Rogers, 1983).

3. Technological competition- here R\&D lab work to improve the innovation to sustain in the competitive market through changing the production process. It is challenging for small firms to enter this market while existing firms drop out due to failure in making improvements on imitation, such as the semiconductor industry (Rogers, 1983).

4. Standardization- here, the development activities focus on further improvement of the production process to make a durable product with competitive price features, for instance, the pocket-calculator industry (Rogers, 1983).

\section{Technology Strategy Model}

Rieck and Dickson (1993) proposed a utilitarian technology strategy model, which is a management theory on how firms can adopt and diffuse technology by incorporating technology strategies into a firm's overall vision. This model is known as the technology strategy model, which is based on six major sequential tasks in the process of technology strategy, such as (1) setting horizons, (2) industry forecasting, (3) technology positioning, (4) determining technology availability, (5) appropriating technology, and (6) managing technology. All these six tasks cover three basic levels of strategy, such as $(1-3)$ cover corporate strategic concerns, $(3-5)$ cover business strategy issues, and $(5-6)$ cover strategic operational concerns.

1. Setting horizons. Setting horizon is the broadcasting aspects of technology strategy in the technological environment or industry where firm operates its activities. It includes strategic benefits of adopting new technology or sector and practical implications of the changes due to the technological adoption which needs strategic analysis. It determines the industrial context and broad directions in the long run of the firm. Thus, setting 
horizons clearly identifies the certain technologies of the firm from where benefits may possibly be obtained. (Rieck \& Dickson, 1993, pp. 400-401).

2. Industry forecasting. Industry forecasting does not necessarily predict about the emergence of new products. It focuses on the understanding of the factors that can affect the industry negatively over the long period and the general direction of development of the industry. It considers how innovative or distinct technologies could be used to reconfigure the value chain, which can bring benefits to the firm. Since the technological revolution significantly impacts the organizational structure, it is critical to sense the new technology that can bring revolution. (Rieck \& Dickson, 1993, pp. 401-402).

3. Technology positioning. In regard to technology, a firm needs to place itself in a position where they believe to be the best fit for them. The technology positioning depends on the strategic direction and potential future business environment. The selection of technology could be made with technology forecasting. The most important thing is to define the way of using technology for competitive advantages. A choice needs to be made at the time when they like to lead the competitors. The firm must decide the most appropriate time to change its technological position over to which it will achieve the target. (Rieck \& Dickson, 1993, pp. 402-404).

4. Determining technology availability. At this stage, the firm will already have developed a comprehensive understanding of the required technology and its significance for the future. Determining technology availability is related to R\&D strategies of the firm. Technology comes from three different sources, such as internal (from R\&D), external (direct purchase, licensing, and knowledge recruitment), and mixed (internal and external). The function of determining technology availability is to enhance technological resources rather than only buying new technology. The very first task is to determine the available internal and external technologies and their competencies for the future. In the long run, technology with better competencies should be targeted in comparison to the existing technologies its competitors have. (Rieck \& Dickson, 1993, pp. 404-405).

5. Appropriating technology. After identifying required technologies and sources, the firm needs to implement those effectively into the operations. Appropriability comprises of two components, such as economic consideration where knowledge is expensive to generate but economical to spread, and effective technology transfer where technology is uncodified. It is difficult to transfer technology when technology is uncodified. Low appropriability limits the achievement from R\&D and hinders the way to technology leadership. Appropriating a technology, the firm needs to allow 1-2 years to train and make the staff understand the technology. (Rieck \& Dickson, 1993, pp. 405-406). 
6. Managing technology. Management of technology is the final component of technology strategy, which ensures operational efficiency. It is a continuous manner for employees to work constantly towards enhancing all aspects of the organization and operations. This gives the organization an internal dynamic movement and numerous small enhancements for incremental gains. The dynamic movement and continuous improvements pave the way to implement new technology more efficiently and make sure to fit the technology into the firm's operations. The continuous improvements also help identify key bottlenecks to make the new technology beneficial for the operations in overcoming the inefficiencies in current technologies. (Rieck \& Dickson, 1993, pp. 407).

\section{Components and functions of SMS}

Several disruptive technologies, such as cyber-physical systems (CPSs), the Internet of Things (IoT), cloud manufacturing, big data analytics, and artificial intelligence (AI) have emerged to enable the SMS in the industry (Park \& Febriani, 2019). Phuyal et al. (2020) added few more components of SMS, such as virtual reality, augmented reality, additive manufacturing, flexible and reconfigurable manufacturing, Industrial Internet of Things (IIoT), and simulation. Additionally, Aneja et al. (2019) pointed out simulation and vertical/horizontal integration of the value chain from management to the shop floor to be the key components of future textile SMS. Based on the above investigation, the key components of an SMS can be listed as follows.

\section{Cyber-physical System (CPS)}

CPS is a multidisciplinary system to control widely distributed and embedded computing systems by combining computation, communication, and control technologies to recognize the real-time and dynamic collaboration between physical and embedded systems (Park \& Febriani, 2019). It is a fusion of the virtual and physical world where the physical world involves computation and vice versa (Aneja et al., 2019). The future SMS will be based on Socio-cyber-physical system (SCPS)-based manufacturing, which is the combination of smart manufacturing (mass customization) and additive manufacturing (mass personalization), adding the social dimension along with. Social dimensions, for example, are law, beliefs, and culture (Yao \& Lin, 2015). In SCPS-based manufacturing, the internet, customers, social media, equipment, and producers interact intensively along with smart and hybrid manufacturing processes ( $\mathrm{Li}$ et al, 2020).

\section{Internet of Things (IoT)}

IoT is a network of cyber physical system that allows to interact between "things" and "object" via internet with each other through unique 
addressing schemes, such as RFID, sensors, and mobile phone (Aneja et al., 2019).

\section{Robotics}

Robotics is an autonomous system that integrates programming, machines, sensors, actuator, digital electronics, and microprocessor technology, which is capable of doing certain activities (Shakhatreh, 2011). Robots are considered a basis of smart manufacturing systems, particularly in the automobile and related component assembly, where human involvement is highly risky and time-consuming. Future industrial robots will occupy a wider range of application areas in the manufacturing industries (Hägele et al., 2016). Applications of robots in the apparel industry have already been started in a small range, especially in sewing operations, which is expected to increase further in the future (Gries \& Lutz, (2018).

\section{Artificial Intelligence (AI)}

Industrial artificial Intelligence (AI) is an organized computational area, which focuses on the development and validation of various machine learning algorithms for industrial applications with longtime performance (Lee et al., 2018). Industrial AI can achieve smart and flexible industrial systems and enables them to defect flexible, on-demand, and self-organizing (Lee et al., 2018). This system can also identify potential threats, forecast, and develop possible action plans. A forecasting tool is an important part of the production plan which is being used in designing the manufacturing process for an uninterrupted production model (Rojek \& Jagodziński, 2012)

\section{Advanced Enterprise Resource Planning (ERP)}

ERP is an information management tool that integrates the entire system of business management and offers a smooth flow of information within the organization (Klaus et al., 2000). SMS needs the integration of personalized and customized connectivity and collaboration of technology and information including Manufacturing Execution System (MES), Internet of Things (IoT), Artificial Intelligence (AI), intelligent algorithms, Engineering Data Analysis (EDA), Supply Chain Management (SCM), and Design Chain Management (DCM) with an integrated information framework which is considered to be possible by ERP (Oztemel \& Gursev, 2018).

\section{Digital Twin}

Digital twin is a virtual model of physical objects to simulate their behaviors to establish the cyber-physical fusion and to achieve the optimization of the product design, manufacturing, and smart services (Qi et al., 2018). A digital twin offers a digital interpretation of the previous and existing behavior of components of SMS. The robust managing capabilities of the digital twin help accelerate the product or system performance with predictive design and process adjustments in the physical world (Burke et al., 2017). 


\section{Additive Manufacturing}

Additive manufacturing is the process of printing 3D objects putting several subsequent layers of materials together using a 3D printer where every slice of the layer is programed by software. It can produce 3D objects of high geometric complexities along with precise control of surface finish and dimensional accuracy ( $\mathrm{Li}$ et al, 2020). In this process, solid goods are conceived of, made, and delivered by using an additive process with an option to mass customization, which connects the cyber and physical systems together (Yao \& Lin, 2015).

\section{Cloud Manufacturing}

Cloud Manufacturing is based on cloud computing and the Internet of Service (IoS) manufacturing system that transforms manufacturing assets and competencies to manufacturing services by offering various value-added services and the option to communicate via different channels (Mabkhot et al. 2018).

\section{Big data}

A big data storehouse offers the extensive capability to store and retrieve the essential data for the value chain of the manufacturing enterprise that provide several benefits, such as the identification of the root causes of failures in real-time, understanding of the potential data-driven marketing, and generation of customer offers as per their feedback (Mabkhot et al. 2018).

\section{Simulation}

Simulation is a programming model based on the mathematical equation that is designed to imitate a real system when the analytical model does not work (Durán, 2020). Simulation is used to predict the performance characteristics of a production system to underline their productivity levels and assess new management solutions within a short time (Bevilacqua et al., 2013).

\section{Vertical and Horizontal Integration}

Vertical integration is the interconnection of different processes within an enterprise, such as sourcing, production, distribution, sales, and other economic processes to reduce cost and optimize the services (Doan, 2007). When the automation system gets connected with management administration network is known as vertical integration and when automation system is interconnected with other automation system is referred to as horizontal integration (Treytl et al., 2005). An example of horizontal integration is Supply Chain Management, where an enterprise seeks to optimize the entire set of activities, such as order entry, purchase, production, and shipment, to minimize the lead-time and costs for production along with maximizing the value for the customer (Wangler \& Paheerathan, 2000).

Liu et al. (2020) patented a smart workshop with the following steps ranging from $\mathrm{A}$ to $\mathrm{D}$. 
Step-A. The initial design plan includes factory spaces, building structure, manufacturing process, distribution format, equipment geometry, and layout of the entire production line. Acquiring a design of a production line is simulated according to the design requirement to establish a three-dimensional digital graphic model of a smart factory with required components. A linear L shaped production line layout is preferred when the manufacturing plant gets a spacious area with different material loading and unloading zones. (Liu et al., 2020).

Step-B. A smart manufacturing system with a rapid custom design method includes a host computer, a simulation system, and a Programmable Logic Controller (PLC) system. This step makes a complete plan of single machine equipment that includes product distribution, motion control plan, and performing the offline simulation. (Liu et al., 2020).

Step-C. At this step, the system establishes a communication system between the Product Life Cycle (PLC) system of smart model and PLC system of physical equipment with the help of digital twin technology. Moreover, there will be an interconnection between data and information, real-time synchronization of physical equipment data, host computer monitoring (ERP/MES) data, and 3D virtual simulation data with the help of binary synchronization technology, which will result in a 3D digital twin model of a smart manufacturing system. It establishes communication between single machine digitization and operation synchronization. MES and digital twin model establish the operation with the help of the Manufacturing Execution System (MES) generated instructions while digital twin model execution gets feedback and establishes a simulation operation. MES simulates the production order, analyzes the operation output, which further verifies the production deadline achievement rate, production balance rate, facility operation rate, vulnerability, and flexibility of the entire production line. (Liu et al., 2020).

Step-D. In the final step, all the systems get integrated and synchronized together, such as single machine equipment, control system, and implementation system with virtual network and 3D digital twin model. The inventors of this system claimed that it significantly shortens the custom design cycle and covers the traditional serialized manufacturing system into a parallelized manufacturing system. The following are some of the distinct optimizations of this system over the traditional system.

- It is a virtual design process of manufacturing, which forms a 3D digital twin model that includes factory layout, equipment operation, and product movement method to optimize the preliminary design.

- It shortens the number of design products and design cycles in a parallelized $R \& D$ process by the integration and synchronization between the virtual control network and the 3D digital twin model. 
- It optimizes the integration cycle of the whole production line by integrating digital twin technology, physical equipment into sections, previous integration, avoiding control logic and design errors, reducing joint test time, shortening the ratio of space occupancy and fund occupancy cost.

\section{Technology Development of SMS}

Sjödin et al. (2018) pointed out three key challenges for developing SMS, such as people, process, and technology. Strengthening research and development is a key notion before developing SMS. Before developing any technology in SMS, certain accesses must be fulfilled, such as automation and robotization, qualified staff, ability to data processing, repeatable production process, readiness to internal and external integration, and access to capital budget (Odważny et al., 2018). Laaper et al. (2020) figured out seven factors to consider in terms of technology development for smart manufacturing system, such as focusing the end-users' need, prioritizing leadership level for technology adoption, identification and deployment of unique skill sets, development and access to skills required for the long term success, capabilities of connectivity, management of digital devices at the shop floor and bridging IT and OT to ensure the transformation. They also stated that the technology in an SMS should combine the capabilities in the Industrial Internet of Things (IIoT), cloud and edge computing, robotic process automation (RPA), artificial intelligence (AI) and machine learning, vision systems, and augmented and virtual reality systems.

The above statements summarize the following factors to consider for the technology development of SMS.

- Researching the end users' need

- Innovation

- Knowledge and workforce management

- Leadership for technology adoption

- Identification, development, and deployment of unique set of skills and skills required for long term success.

- Internal and external technology and management integration.

- Capabilities of connectivity

- Bridging between IT and OT

- Management of digital devices at the shop floor

\section{Technology Management Strategy in SMS}

Mittal et al. (2018) stated six technology management strategies to adopt SMS in the enterprise as follows. 
Decision making. Strategic decision-making starts with the identification and verification of information pertaining to the expected change. It is followed by the external or internal development of alternative solutions or designing the brand-new solutions that can fit the new changes. Finally, the new solutions are evaluated by the managers to come up with a best-fit solution to apply (Brouthers et al., 1998). A rational decision-making process must locate, access, retrieve, analyze, and utilize information before reaching to a decision. The strategic decision includes the information on internal organization, market structures, customers' attitudes, competitors, technologies, regulations, and public affairs (Citroen, 2011).

Knowledge management. Knowledge is the integration of information, skills, and capability toward a set of objectives, whereas knowledge management is the acquisition, transfer, and accumulation of knowledge (Gaimon \& Bailey, 2012). Knowledge management and development include capabilities of firm's technical systems, workforce management, and consistent transfer of knowledge across the firm (Gaimon, 2008). The internal knowledge can be shared with a competitor in the same market by licensing or competitive mechanism, which is another way of making a marginal profit (Gaimon et al., 2017). Research and Development (R\&D) set up at the initial stage is expensive for the organizations. Thus, technology trade or joint venture has been important for the growth and diversification and developing relationships with other organizations for a long time in a cheaper way (Granstrand, 2004). Technology standards. Standards are published files to act as a basis for product and process development. Technology standard is the specific technical resolution that is taken to carry out a certain function. It makes products and services up to certain obligations for entering a particular market and helps the developers and users decide the best technical protocols for dynamic functions and services (Jiang et al., 2020). Technology standard provides compatibility and effective operations which ultimately offers huge economic benefits (Xu et al, 2014).

Legal policies. The common legal policies of manufacturing industries, especially the automotive industry, include warranty, intellectual properties, cybersecurity, data privacy, tariff, and global commodities impacting sourcing (Aiello \& Miller, 2020).

Sustainability guidelines. Sustainability in the manufacturing system includes sustainable product lifecycle issues in the manufacturing process that aims at effective use of raw materials, energy, information, and capacity for work (Ioannou \& Veshagh, 2011). A sustainability guideline brings the balance of demands from economic, ecological, and technological perspectives (Price et al., 2011). Many SMEs often do not focus on sustainability due to lack of time, personnel, skills, and financial capabilities but an environmental focus in the enterprises offers both technological advances and improved outlook toward 
creating end user-friendly production (Price et al., 2011). Ioannou and Veshagh (2011) highlighted several points that are required to include in the sustainability guidelines of SMS as follows.

- Reduced use of energy, materials, and water.

- Improvement of environmental aspects of resources, such as toxic and ecologically incompatible chemical substances.

- Designing for multiple and longer life cycles of system and products.

- Improvement of manufacturing technology in terms of environmentally sound production technologies and processes.

- Improvement of working conditions, such as ergonomic point of views, health and safety requirements; equity and fairness; employees' personal development.

- Supporting local communities in economic, social, and cultural perspectives.

\section{Characteristics of SMS}

Mabkhot et al. (2018) pointed out six characteristics that need to be taken into consideration for designing an SMS, such as modularity, interoperability, decentralization, virtualization, service orientation, and real-time capability.

\section{Modularity}

Modularity is the characteristics ability of separation and reunion to form different configurations in the system (Mittal et al., 2019). This characteristic enables SMS to separate and reconfigure different modules from different vendors in the quick possible time. It provides SMS with a real-time capability to respond to the changes as per new requirements, which helps overcome internal difficulties (Mabkhot et al., 2018).

\section{Heterogeneity}

Heterogeneity is the variety of dissimilarities in different units and components, unlike modularity. SMS is a heterogeneous system that comprises of diversified and dissimilar units and components (Mittal et al., 2019).

\section{Interoperability}

Interoperability is the ability to exchange and share information across the different unit of SMS (Mittal et al., 2019). It indicates the ability to communicate technical information across the system components and between manufacturing enterprises and customers. Standardized mechanical, electrical, communication information, and semantic technologies are key enablers of interoperability for the SMS (Mabkhot et al., 2018).

\section{Intelligent Control}

Intelligent technology enables a system to change its action by its own experience, whereas intelligent control technology integrates different 
technology, such as AI techniques, to manage its mechanisms (Mittal et al., 2019). It can control and exploit the manufacturing process when necessary. For instance, when any raw material is sent to any unit, the manufacturing unit can process that raw material automatically. It can also control the maintenance of the system by predictive maintenance capability to get rid of the machine idle time (Tao et al., 2018)

\section{Data-Driven and Connected System}

SMS is a data driven system that connects each and every component sharing and exchanging data. It is a networked, connected, and shared manufacturing system based on information communication technology (Kusiak, 2019). Moreover, incorporation of Computer Integrated Manufacturing (CIM) and advanced Enterprise Resource Planning (ERP) facilitate the usage of computer networks across the interconnected production system by integrating advanced technologies in different functional areas effectively to achieve the goal of the enterprise (Nagalingam \& Lin, 1999; Oztemel \& Gursev, 2018)

\section{Sustainability}

Manufacturing system is considered to be a significant source of damaging the environment due to its high energy consumption with expected efficiency. In this regard, SMS is a sustainable system in terms of low energy consumption and with considerable factors in favor of consumers and environmental aspects (Kusiak, 2019). The production process and operation system should be with minimum environmental disruption in terms health, chemicals, and environmental hazards (Mittal et al., 2019).

\section{Decentralization}

Decentralization allows the system elements, for instances modules, material handling, and products to be independent of control unit to make decisions on their own according to the organizational objectives. All these system elements allow related workers to make decisions on simple issues in time and cope with the strategic directions and changes in the manufacturing environments (Mabkhot et al., 2018).

\section{Virtualization}

Virtualization creates an artificially simulated environment similar to the real environment to supervise and replicate physical processes. It helps the system implement designs, create digital prototypes similar to the actual one to check, modify, and test before proceeding to the physical system (Mabkhot et al., 2018).

\section{Real-time capability}

The real-time capability enables the system to act in response to adjustments of the internal production system in time, such as malfunctions and resource failures. In order to achieve this capability, the system should have a sufficient degree of modularity and real-time monitoring and 
controlling capacity to reconfigure the required adjustments (Mabkhot et al., 2018).

\section{An SMS Based Apparel and Textile Industry Model}

Being a traditional industry, the textile industry faces global competition for rapid change of trend and dynamism of customer demands that need the upgraded technology, manufacturing intelligence, and managerial strategy (Ku et al., 2020). Textile and apparel industries are going forward to embracing SMS based on Cyber-Physical System (CPS) by incorporating IoT technology in the existing infrastructure to make the manufacturing system smarter. CPS system in the textile and apparel industry integrates ordering systems, automation systems, product information, and management system, production information integration, and production automation system (Lee et al., 2017). Textile industry encounters worldwide competition for rapid and dynamic change in fashion and styles, which results in frequent mass customization (Ku et al., 2020). To adopt these changes by the textile companies, the operation and process systems need to be upgraded by employing the latest manufacturing intelligence (Ku et al., 2020). The textile industry is gradually adopting CPS as a part of the upgrade to the fourth industrial revolution or Industry 4.0 (Ślusarczyk et al., 2019). With the growing connectivity of smart operations across the textile and apparel value chain, smart products and data-driven services have increased over $20 \%$, resulting in $10 \%-40 \%$ cost savings in servicing and maintenance, which expedited the lead time 20\%-50\% (Küsters et al., 2017). Additionally, smart connected products provide a technological basement for integrating new business models or data-driven business models that paves the way to earn more revenue (Küsters et al., 2017).

Gökalp et al. (2018) proposed an SMS of apparel production unit that includes six smart approaches to integrate a smart manufacturing system as follows.

\section{Digital Information Transfer}

- Digital modeling, drawing and pattern making of garment sketch by 3D format.

- Testing the model and sketch by virtual reality technology.

- Sending the patterns and markers to the cutting section by cloud technology.

\section{Predictive Maintenance}

- Defining a maintenance strategy with variety of data analytics on hidden pattern and relationship of devices in order to increase efficiency and reduce failure rate.

- A CPS including sensors, actuators, processors, and intelligent electronics with internet to optimize the functionality and device problem in real time. 


\section{Human-robot Collaborated Cutting}

- Transporting fabrics from fabric store by the CPS.

- Spreading fabrics on the cutting table by the CPS.

- Completing the cutting by a laser cutting system with minimum human interaction.

\section{Intelligent Manufacturing}

- Placing Radio Frequency Identification (RFID) tags on the cut fabrics having information on how to sew, iron, button, wash, and pack.

- Based on the information of the RFID tag, the respective parts will follow the manufacturing sequence by the cyber-physical system, whereas the manufacturing supplies will also be arranged as per the RFID information.

- RFID readers will set the required action to complete steps, such as types of button, wash temperature, and ironing temperature.

\section{Robotic Quality Control}

- Computer aided quality control system will speed up the quality assurance of the product.

- Advanced image processing and machine learning will provide the capability of determining the best quality of the final garments.

\section{Packaging with Cyber-physical System}

- Based on the RFID information, the final product will be packed by cyber-physical system with minimum human interactions.

- RFID tags will still be available on the product for retailers and consumers' accessibility of product information.

\section{Challenges of implemention:}

The previous discussions from theoritial relevances and components of SMS indicate that SMS is a very challenging system to adopt as it offers new technology and pattern of machine setting. The thoeritical relevances figured out the challenges that relate to innovation, development, and management of SMS. The prvious literature included several challenges and difficulties that relate to impliment SMS from manual setting to Industry 4.0 version. Phuyal et al. (2020) and Tuptuk and Hailes (2018) indicated that the security was the main difficulty to implement this platform as it is based on internet, computer, software, and data sharing platform. Other challenges were identified as system integration, interoperability, safe human-robot collaboration, multilingualism, and return of investment.

\section{Findings and implications}

The overall review showed that the theoritical perspectives can demonstrate the need for technology knowledge to adopt and spread the 
development and management of smart manufacturing system. Theory makes the complex technological structure easy towards the innovators, new adopters, and managerial officials. IoD thory identified communication channel and social system as the integral part of technology innovation, while innovation, immitation, technological competition, and standardization are the major parts of technology development. On the other hand, technology strategy model discussed readiness, futuristic goal, technology positioning, understanding, identifying, and manging are the key processes of technology management. Several disruptive technologies, such as cyber-physical systems (CPSs), the Internet of Things (IoT), cloud manufacturing, big data analytics, and artificial intelligence (AI) have been identified as the major enablers of the SMS in the industry. Decision making, knowledge management, techology standards, legal policies, and sustainability guidelines have been found to be the strategic aspects for technology management of SMS. Characteristically SMS is mostly unique for decentralization, virtualization, and real time capabilities. The future manufcaturing system is supposed to be the base of SMS. This study could help the respective future researchers and stakeholders connect with the theoritical relevance to understand the inital development and management complexities of the industry 4.0 level of manufacturing system. The future research could be on the optimization of addaptibility of SMS. Different addaptive models could be developed for different manufacturing areas. A step by step process of implementation would offer a flexible understanding of the complexities. However, a common addaptive model would be something interesting in future research for generalized view of the this disturptive manufacturing system.

\section{Conclusion}

Theory can explain the technical aspects of any phenomenon that helps the respective stakeholders perceive the primary complexities. However, many scholars are still skeptic on the effectiveness of theoretical relevance to technology understanding. SMS is a very new paradigm of manufacturing system that integrates many disruptive technologies offering unprecendented complexities. The idea of theoretical perspectives can expedite the process of adopting its primary difficulties. Rogers' DoI theory can help the early adopters to think innovatively including different phases of technology development. On the other hand, technology strategy model can help the adopters perceive the adoptions and diffuse the technology across the firm. The integration of theoretical knowledge into the technical perspectives makes the primary understanding on SMS, its components, and characteristics more acceptable. This study has combined the theory and technical knowledge on the management of SMS incorporating a patent and model SMS of global textile complex. The study adresses the challenges and opportunities to cope 
with the management and dynamic nature of this manufacturing system that can offer a robust primary understanding for the researchers, early adopters, future researchers, and respective stakeholders to develop and manage it in the working environment.

\section{References:}

1. Aiello, M., \& Miller, V. (2020). The impact of emerging technology on global supply chains. The National Law Review. X (310). https://www.natlawreview.com/article/top-legal-issues-facingautomotive-industry-2020

2. Bevilacqua, M., Ciarapica, F. E., Crosta, A., Mazzuto, G., \& Paciarotti, C. (2013). Designing an Efficient Production System: A Case Study of a Clothing Company. International Journal of Engineering Business Management. 10.5772/56842

3. BoF (2016). The Robot Opportunity. https://www.businessoffashion.com/articles/fashion-tech/therobotics-opportunity-manufacturing-efficiencies

4. Brouthers, K. D., Andriessen, F., \& Nicolaes, I. (1998). Driving blind: Strategic decisionmaking in small companies. Long Range Planning, 31(1), 130-138. doi:10.1016/s0024-6301(97)00099-x

5. Burke, R., Mussomeli, A, Laaper, S., Hartigan, M., Sniderman, B. (2017). Smart Factory: responsive, adaptive, connected manufacturing. Deloitte Insights. https://www2.deloitte.com/us/en/insights/focus/industry-4-0/smartfactory-connected-manufacturing.html

6. Calinescu, A., Efstathiou, J., Schirn, J., \& Bermejo, J. (1998). Applying and assessing two methods for measuring complexity in manufacturing. Journal of the Operational Research Society, 49(7), 723-733.

7. Citroen, C. L. (2011). The role of information in strategic decisionmaking. International journal of information management, 31(6), 493501.

8. Doan, K., L., N. (2007). Vertical integration. Center for Asean studies. file:///C:/Users/MDB173 1.AL/AppData/Local/Temp/CAS55ISSN.pdf

9. Durán, J. M. (2020). What is a Simulation Model? Minds and Machines. 10.1007/s11023-020-09520-z

10. Feng, S. C., Bernstein, W. Z., Hedberg, T., \& Barnard Feeney, A. (2017). Toward knowledge management for smart manufacturing. Journal of computing and information science in engineering, 17(3). 
11. Gaimon, C. (2008). The management of technology: A production and operations management perspective. Production and Operations Management, 17(1), 1-11.

12. Gaimon, C., \& Bailey, J. (2012). Knowledge Management for the Entrepreneurial Venture. Production and Operations Management, 22(6), 1429-1438. doi:10.1111/j.1937-5956.2012.01337.x

13. Gaimon, C., Hora, M., \& Ramachandran, K. (2017). Towards Building Multidisciplinary Knowledge on Management of Technology: An Introduction to the Special Issue. Production and Operations Management, 26(4), 567-578. doi:10.1111/poms.12668

14. Granstrand, O. (2004). The economics and management of technology trade: towards a pro-licensing era? International Journal of Technology Management, 27(2/3), 209. doi:10.1504/ijtm.2004.003953

15. Gries, T., \& Lutz, V. (2018). Application of robotics in garment manufacturing. Automation in Garment Manufacturing, 179-197. 10.1016/b978-0-08-101211-6.

16. Gries, T., \& Lutz, V. (2018). Application of robotics in garment manufacturing. Automation in Garment Manufacturing, 179-197. doi:10.1016/b978-0-08-101211-6.00008-2

17. Hägele, M., Nilsson, K., Pires, J. N., \& Bischoff, R. (2016). Industrial Robotics. Springer Handbook of Robotics, 1385-1422. doi:10.1007/978-3-319-32552-1_54

18. https://www.theseus.fi/bitstream/handle/10024/37806/Shakhatreh_Fa reed.pdf?sequen

19. Ioannou, K., \& Veshagh, A. (2011). Managing Sustainability in Product Design and Manufacturing. Glocalized Solutions for Sustainability in Manufacturing, 213-218. doi:10.1007/978-3-64219692-8_37

20. Jayatilake, H., \& Rupasinghe, T. D. (2016). Implementing Industry 4.0 in the apparel industry; A study to design a customized smart apparel production plant. In presented at the Simulation and Modelling Design Competition, At Department of Industrial Management, University of Kelaniya.

21. Jiang, H., Gao, S., Zhao, S., \& Chen, H. (2020). Competition of technology standards in Industry 4.0: An innovation ecosystem perspective. Systems Research and Behavioral Science, 37(4), 772783.

22. Klaus, H., Rosemann, M., \& Gable, G. G. (2000). What is ERP?. Information systems frontiers, 2(2), 141-162

23. Krzywdzinski, M. (2017). Automation, skill requirements and labouruse strategies: high-wage and low-wage approaches to high-tech 
manufacturing in the automotive industry. New Technology, Work and Employment, 32(3), 247-267.

24. Kusiak, A. (2019). Fundamentals of smart manufacturing: a multithread perspective. Annual Reviews in Control, 47, 214-220.

25. Küsters, D., Praß, N., \& Gloy, Y. S. (2017). Textile Learning Factory 4.0-Preparing Germany's Textile Industry for the Digital Future. Procedia Manufacturing, 9, 214-221.

26. Laaper, S., Dollar, B., Cotteleer, M., Sniderman, B. (2020). Implementing the smart factory: New perspectives for driving value. Deloitte https://www2.deloitte.com/us/en/insights/topics/digitaltransformation/smart-factory-2-0-technology-initiatives.html

27. Lee, J., Bae, Z., \& Choi, D. (1988). Technology development processes: A model for a developing country with a global perspective. $R \& D \quad$ Management, $\quad 18(3), \quad 235-250 . \quad 10.1111 / \mathrm{j} .1467-$ 9310.1988.tb00590.x

28. Lee, J., Davari, H., Singh, J., \& Pandhare, V. (2018). Industrial Artificial Intelligence for Industry 4.0-based Manufacturing Systems. Manufacturing Letters. 10.1016/j.mfglet.2018.09.002

29. Li, L., Zheng, Y., Yang, M., Leng, J., Cheng, Z., Xie, Y., . . Ma, Y. (2020). A survey of feature modeling methods: Historical evolution and new development. Robotics and Computer-Integrated Manufacturing, 61, 1.

30. Li, Q., Tang, Q., Chan, I., Wei, H., Pu, Y., Jiang, H., ... \& Zhou, J. (2018). Smart manufacturing standardization: Architectures, reference models and standards framework. Computers in Industry, 101, 91-106.

31. Liu, Q., Leng, J., Zhang, D., Chen, X., \& Lijun, W. E. I. (2020). Method and system for quick customized-design of intelligent workshop U.S. Patent Application No. 16/820,638. US20200249663A1

32. Lu, Y., \& Ju, F. (2017). Smart manufacturing systems based on cyberphysical manufacturing services (CPMS). IFAC-PapersOnLine, 50(1), 15883-15889.

33. Mabkhot, M. M., Al-Ahmari, A. M., Salah, B., \& Alkhalefah, H. (2018). Requirements of the smart factory system: a survey and perspective. Machines, 6(2), 23.

34. Majeed, A. A., \& Rupasinghe, T. D. (2017). Internet of things (IoT) embedded future supply chains for industry 4.0: An assessment from an ERP-based fashion apparel and footwear industry. International Journal of Supply Chain Management, 6(1), 25-40.

35. Mario, C. (2019). Theories of the evolution of technology based on processes of competitive substitution and multi-mode interaction 
between technologies. Journal of Economics Bibliography, 6 (2), pp. 99-109

36. McCarthy, I. P. (2003). Technology management-a complex adaptive systems approach. International Journal of Technology Management, 25(8), 728-745.

37. Mittal, S., Khan, M. A., Romero, D., \& Wuest, T. (2019). Smart manufacturing: characteristics, technologies and enabling factors. Proceedings of the Institution of Mechanical Engineers, Part B: Journal of Engineering Manufacture, 233(5), 1342-1361.

38. Nagalingam, S. V., \& Lin, G. C. (1999). Latest developments in CIM. Robotics and Computer-Integrated Manufacturing, 15(6), 423-430.

39. Neto, P., \& Moreira, A. P. (2014). Preface for the special issue on robotics in smart manufacturing. The International Journal of Advanced Manufacturing Technology, 85(1-4), 1-1. 10.1007/s00170014-6028-8

40. Odważny, F., Szymańska, O., \& Cyplik, P. (2018). Smart Factory: the requirements for implementation of the Industry 4.0 solutions in FMCG environment-case study. LogForum, 14(2).

41. Oztemel, E., \& Gursev, S. (2018). Literature review of Industry 4.0 and related technologies. Journal of Intelligent Manufacturing. 10.1007/s10845-018-1433-8

42. Park, H. S., \& Febriani, R. A. (2019). Modelling a Platform for Smart Manufacturing System. Procedia Manufacturing, 38, 1660-1667.

43. Phaal, R., Farrukh, C. J., \& Probert, D. R. (2004). Technology roadmapping - a planning framework for evolution and revolution. Technological forecasting and social change, 71(1-2), 5-26.

44. Phuyal, S., Bista, D., \& Bista, R. (2020). Challenges, Opportunities and Future Directions of Smart Manufacturing: A State of Art Review. Sustainable Futures, 2, 100023. 10.1016/j.sftr.2020.100023

45. Price, S., Pitt, M., \& Tucker, M. (2011). Implications of a sustainability policy for facilities management organisations. Facilities, 29(9/10), 391-410. 10.1108/02632771111146314

46. Qi, Q., Tao, F., Zuo, Y., \& Zhao, D. (2018). Digital twin service towards smart manufacturing. Procedia Cirp, 72, 237-242.

47. Qu, Y. J., Ming, X. G., Liu, Z. W., Zhang, X. Y., \& Hou, Z. T. (2019). Smart manufacturing systems: state of the art and future trends. The International Journal of Advanced Manufacturing Technology, 103(912), 3751-3768.

48. Ren, S., Zhang, Y., Liu, Y., Sakao, T., Huisingh, D., \& Almeida, C. M. (2019). A comprehensive review of big data analytics throughout product lifecycle to support sustainable smart manufacturing: a 
framework, challenges and future research directions. Journal of cleaner production, 210, 1343-1365.

49. Rieck, R. M., \& Dickson, K. E. (1993). A model of technology strategy. Technology Analysis \& Strategic Management, 5(4), 397412. 10.1080/09537329308524145

50. Rogers, E.M. (1983). Diffusion of innovations (3rd ed.). New York: Free Press.

51. Sahin, I. (2006). Detailed review of Rogers' diffusion of innovations theory and educational technology-related studies based on Rogers' theory. The Turkish Online Journal of Educational Technology, 5(2), 14-23.

52. Shakhatreh, F. (2011). The Basics of Robotic (Master's thesis). Lahti University, Syksy, Finland.

53. Sjödin, D. R., Parida, V., Leksell, M., \& Petrovic, A. (2018). Smart Factory Implementation and Process Innovation: A Preliminary Maturity Model for Leveraging Digitalization in Manufacturing Moving to smart factories presents specific challenges that can be addressed through a structured approach focused on people, processes, and technologies. Research-Technology Management, 61(5), 22-31.

54. Ślusarczyk, B., Haseeb, M., \& Hussain, H. I. (2019). Fourth Industrial Revolution: a Way Forward to Attain Better Performance in the Textile Industry. Engineering Management in Production and Services, (2), 52-69.

55. Tao, F., Qi, Q., Liu, A., \& Kusiak, A. (2018). Data-driven smart manufacturing. Journal of Manufacturing Systems, 48, 157-169.

56. Thomas, J. (2017). Scholarly views on theory: Its nature, practical application, and relation to world view in business research. International Journal of Business Management, 12(9).

57. Treytl, A., Palensky, P., \& Sauter, T. (2005). Security considerations for energy automation networks. IFAC Proceedings Volumes, 38(2), 158-165.

58. Wangler, B., \& Paheerathan, S. J. (2000). Horizontal and vertical integration of organizational IT systems. Information Systems Engineering.

59. Xu, L. D., He, W., \& Li, S. (2014). Internet of Things in Industries: A Survey. IEEE Transactions on Industrial Informatics, 10(4), 22332243. 10.1109/tii.2014.2300753

60. Yao, X., \& Lin, Y. (2015). Emerging manufacturing paradigm shifts for the incoming industrial revolution. The International Journal of Advanced Manufacturing Technology, 85(5-8), 1665-1676. 10.1007/s00170-015-8076-0 
61. Zheng, P., Sang, Z., Zhong, R. Y., Liu, Y., Liu, C., Mubarok, K., ... \& $\mathrm{Xu}, \mathrm{X}$. (2018). Smart manufacturing systems for Industry 4.0: Conceptual framework, scenarios, and future perspectives. Frontiers of Mechanical Engineering, 13(2), 137-150.

62. Phuyal, S., Bista, D., \& Bista, R. (2020). Challenges, opportunities and future directions of smart manufacturing: a state of art review. Sustainable Futures, 2, 100023.

63. Tuptuk, N., \& Hailes, S. (2018). Security of smart manufacturing systems. Journal of manufacturing systems, 47, 93-106.

64. Rojek, I., \& Jagodziński, M. (2012, March). Hybrid artificial intelligence system in constraint based scheduling of integrated manufacturing ERP systems. In International Conference on Hybrid Artificial Intelligence Systems (pp. 229-240). Springer, Berlin, Heidelberg.

65. Mittal, S., Khan, M. A., \& Wuest, T. (2016, July). Smart manufacturing: characteristics and technologies. In IFIP International Conference on Product Lifecycle Management (pp. 539-548). Springer, Cham.

66. Mittal, S., Romero, D., \& Wuest, T. (2018, August). Towards a smart manufacturing maturity model for SMEs (SM 3 E). In IFIP international conference on advances in production management systems (pp. 155-163). Springer, Cham.

67. Aneja, A., Kupka, K., Militky, J., \& Kadi, N. (2019, July). TEXTILE INDUSTRY 4.0-PREPARING FOR DIGITAL FUTURE. In Proceedings of the 19th World Textile Conference-Autex 2019 (pp. 6$6)$.

68. Gökalp, E., Gökalp, M. O., \& Eren, P. E. (2018). Industry 4.0 Revolution in Clothing and Apparel Factories: Apparel 4.0. Industry 4.0 From the Management Information Systems Perspectives, 169184. 